\title{
Influence of the body mass index on the remote outcomes after the first myocardial infarction
}

\author{
Oxana Akulova* \\ Kurgan State Budget Establishment "Kurgan Regional Cardiology Centre", Kurgan, Russia
}

Objectives: To estimate the influence of an index of weight of a body (BMI) on a lethality and survival after the first myocardial infarction in the remote period.

Patients and Methods: Patients after the first myocardial infarction, which happened in 1996-1998, all men ( $\mathrm{n}=232$ ), mean age $48.6 \pm 5.52$. Supervision median 116.4 months (9.7 years), the maximal 170 months (14.2 years). During the supervision, 108 people died of a cardiovascular disease, and 124 persons remained alive. Patients were arranged in 4 groups on the size of initial BMI: I. BMI <22; II. BMI from 22 to 24,9; III. from 25,0 to 29,9; IV. BMI 30. Group selection with BMI less than 22, instead of less than 18,5 (as index of an underweight of a body by criteria of VOZ, 1997 of $\mathrm{g}$ ) is caused by that the least BMI on all group of supervision made 20. BMl was calculated by means of an index of Ketle $\left(\mathrm{kg} / \mathrm{m}^{2}\right)$, establishment of the fact of existence of level of interrelation - by means of criterion a chi-square, for a connection assessment between BMI and a lethality the index of the relative risk (RR) was used, reliability of results was estimated on Student's criterion (t), statistically reliable distinctions were considered at $p<0.01$.

Results: In the group of the dead average BMI made 26.65 \pm 3.56 , in the group of the survived BMI was $25.84 \pm 4.27-$ groups authentically did not differ in size BMI (to $t=3.4$; $\mathrm{p}<0.05)$. The fact of existence of reliable interrelation between criterion of IMT and the remote lethal outcome of a postmyocardial infarction cardiosclerosis was not established $\left(\chi^{2}=1.186\right.$, number of degree of freedoms of $\mathrm{df}=2$, $p=1.0$ ), however, depending on size BMl changed RR. The risk of death made 1.4, 1.01, 1.01 and 0.77 among persons with BMI less than 22, 22-24.9, 25-29.9 and 30 and more respectively. The relative risk of death was lower in patients with $\mathrm{BMI} \geq 30$ in comparison with patients with $\mathrm{BMI}$ from 22 to $24.9\left(\mathrm{RR}=0.75, \chi^{2}<0.01\right)$ and with $\mathrm{BMI}$ less than 22 $(\mathrm{RR}=0.55, \mathrm{p}<0.05)$. The relation of risk to die to the survived made 0.77 in the group with $\mathrm{BMI} \geq 30$, chances in groups with $\mathrm{BMl}=22-24.9$ and with $\mathrm{BMI}=25-29.9$ did not change, chances (RR to 1.4) - in the group with $\mathrm{BMI}<22$ increased.

Conclusions: BMI is not a reliable predictor of the remote prognosis after the primary myocardial infarction. With a known share of probability the risk of death in the remote postmyocardial infarction period increases in persons with BMI less than 22 and decreases with BMI 30 and more.

KEYWORDS: body mass index, myocardial infarction, prognosis.

CITATION: Cardiol Croat. 2013;8(9):316.

Received: $29^{\text {th }}$ Jun 2013

*Address for correspondence: Kurgan State Budget Establishment "Kurgan Regional Cardiology Centre” 24, Volodarsky St., Kurgan, 640000 Russia.

Phone: +79129731229

E-mail: akulaox@mail.ru

\section{Literature}

1. Tantsyreva IV, Volkova EG. Survival and relative risk of death of elderly and senile men with ischemic disease with traditional risk factors. Bulleten' Sibirskogo otdeleniâ Rossijskoj akademii medicinskih nauk. 2009;135(1):42-7. http://old.soramn.ru/Journal/2009/N1/p42-47.pdf 